Vol 10, Issue 11, 2017

\title{
CROSS-SECTIONAL STUDY OF SURGICAL PROPHYLACTIC ANTIBIOTIC ADMINISTRATION IN MARZOEKI MAHDI HOSPITAL, BOGOR, INDONESIA
}

\author{
NISA NAJWA ROKHMAH, RETNOSARI ANDRAJATI, MAKSUM RADJI*
}

Faculty of Pharmacy, University of Indonesia, Depok, West Java, 16424, Indonesia. Email: maksumradji@gmail.com

Received: 27 May 2017, Revised and Accepted: 13 July 2017

ABSTRACT

Objective: This study was conducted to evaluate the prophylactic antibiotic administration in the surgical clinic of Dr. H. Marzoeki Mahdi Hospital, Bogor, Indonesia.

Methods: The data were assessed from the medical records of all patients who underwent surgery from January to December 2013 retrospectively. Antibiotic prophylaxis was assessed based on the Scottish Intercollegiate Guidelines and the National Guidelines of Antibiotic Usage, which includes the type, time, and duration of prophylactic administration of antibiotics.

Results: A total of 577 patients were included in this study, consisting of 202 men and 375 women. The most frequently performed surgery is a common surgery 347 (60.1\%), followed by obstetric operations 176 (30.5\%), and orthopedic surgery 54 (9.4\%). In this study, all patients received prophylactic antibiotics before surgery. Cefotaxime $(87.8 \%)$ was the most commonly used antibiotics for surgical prophylaxis. Of the 577 patients, only $1.1 \%$ of patients reported with surgical site infection (SSI).

Conclusion: This study shows that adherence to the guidelines of surgical antibiotic prophylaxis is still very low. Therefore, efforts should be made to increase the compliance of using antibiotic prophylaxis in accordance with standard guidelines to improve the rational use of antibiotics.

Keywords: Antibiotic prophylaxis, Surgery, Surgical site infection

(C) 2017 The Authors. Published by Innovare Academic Sciences Pvt Ltd. This is an open access article under the CC BY license (http://creativecommons. org/licenses/by/4. 0/) DOI: http://dx.doi.org/10.22159/ajpcr.2017.v10i11.20286

\section{INTRODUCTION}

Surgical site infections (SSIs) are one of the most important causes of healthcare-associated infections occur when an invasive surgical procedure performed. The incidence of SSIs monitored for 30 days after surgery [1]. It is still a major cause of post-operative morbidity and mortality. In addition, surgical wound infections can prolong hospitalization and increase the cost of medical care in hospitals [2]. Therefore, almost surgery should be given prophylactic antibiotics to reduce the incidence of SSI. The use of appropriate antibiotic prophylaxis in surgery is quite effective in reducing mortality and health care costs associated with infection after surgery [3]. However, the compliance to surgical guidelines for antibiotic prophylaxis in some countries is still varies including in Indonesia [4-6]

Several studies showed that the rate of compliance with guidelines for the use of surgical prophylactic antibiotics ranging from $0 \%$ to $71.9 \%[6,7]$. In developed countries, the level of compliance with prophylactic antibiotics is higher than in developing countries. The inappropriateness in administration of prophylactic antibiotics can increase the emergence of antimicrobial resistance worldwide.

In Indonesia, the study on the use of antibiotic prophylaxis is still rarely done. Some studies have shown that the compliance of prophylactic antibiotic administration still very poor [5,6,8]. Dr. H. Marzoeki Mahdi Hospital is one of the main referral hospitals in Bogor where emergency and elective surgery done in this hospital. However, study to assess the rational use of antibiotic prophylaxis has not been performed. Therefore, this study was conducted to evaluate the administration of surgical antibiotic prophylaxis at this hospital.

\section{METHODS}

A cross-sectional study was conducted at the Surgical Department, in the Dr. H. Marzoeki Mahdi Hospital, Bogor Indonesia, during the year of 2013. All patients who underwent surgery were included in this study. Exclusion criteria: Patients who have received antibiotic therapy before surgery, post-operative condition cannot be followed, and patients with incomplete medical records. Medical data of patients who performed surgery in the surgical clinic included patient demographics, kind of surgical procedure, choice of antibiotic regimens, time of administration, and dosage were collected retrospectively. The compliance of prophylactic antibiotics administration was based on Scottish Intercollegiate Guidelines Network (SIGN) [9].

This study was obtained ethical permission No. DL. 02. 03.097 dated February 17, 2014, from the ethical committee of Dr. H. Marzoeki Mahdi Hospital.

\section{RESULTS}

During January to December 2013, a total of 577 patients of surgical clinic of Dr. H. Marzoeki Mahdi Hospital were enrolled and met the inclusion criteria. There were 202 males and 375 women. The demographic data are given in Table 1 . The most frequent surgeries performed was general surgery 347 (60.1\%), followed by gynecologic and obstetric surgery 176 (30.5\%), and orthopedic surgery 54 (9.4\%). In this study, all patients were received prophylactic antibiotics before surgery. Cefotaxime and ceftriaxone were the most frequent antibiotic used for the surgical prophylaxis, $87.8 \%$ and $9.4 \%$, respectively. The incidence of SSI was $1.1 \%$.

\section{DISCUSSION}

The incidence of SSI in our study was $1.1 \%$ that is lower than reported of SSI incidence rates worldwide of 2.6\%-41.9\% [10-12] and lower than the incidence rate of SSI that reported in some hospital in Indonesia, which is ranging from $2.3 \%$ to $21.1 \%[5,6,8]$.

The patients with surgical wound infections had an ASA score of $1(66.7 \%)$. In general, the risk of infection depends on the value of ASA, where the higher the value of ASA, the higher the risk of infection [13]. 
Table 1: Demographic data and antibiotic and antibiotic prophylactic used in this study

\begin{tabular}{ll}
\hline Characteristic & N (\%) \\
\hline $\begin{array}{l}\text { Number of patients } \\
\text { Gender }\end{array}$ & $577(100)$ \\
Males & $202(35.1)$ \\
Females & $375(65.9)$ \\
Age (years) & \\
<20 & $68(11.8)$ \\
$20-39$ & $279(48.4)$ \\
$40-59$ & $157(27.2)$ \\
$\geq 60$ & $73(12.6)$ \\
Type of surgery & \\
Obstetrics & $176(30.5)$ \\
General surgery & $347(60.1)$ \\
Orthopedic surgery & $54(9.4)$ \\
Duration of surgery (hrs) & \\
<1 & $527(91.3)$ \\
1-2 & $41(7.1)$ \\
$>2$ & $9(1.6)$ \\
Antibiotics & \\
Amoxicillin & $14(2.4)$ \\
Cefotaxime & $374(64.8)$ \\
Ceftriaxone & $54(9.4)$ \\
Metronidazole & $1(0.2)$ \\
Streptomycin & $3(0.5)$ \\
Netilmicin sulfate & $4(0.7)$ \\
Number of patient with SSI & $6(1.1)$ \\
\hline
\end{tabular}

SSI: Surgical site infection

This study showed that the third-generation of cephalosporin, cefotaxime (87.8\%) was the preferred used antibiotics as a surgical antibiotic prophylaxis. The third-generation cephalosporin was used by surgeons because cefotaxime is abroad-spectrum antibiotic which is expect to reduce the rate of SSI. In our study, a third-generation cephalosporin was prescribed for almost patients who received antibiotic prophylaxis that was not in accordance with the SIGN guidelines [9]. Interestingly, ceftriaxone is also used as a surgical prophylactic antibiotic in some hospitals in Indonesia [5,6,8]. The previous study showed that the antimicrobial agent's cefotaxime was the most commonly prescribed as antibiotic prophylaxis in surgery [9].

In some guidelines of surgical prophylactic antibiotic, the firstgeneration cephalosporin is recommended for various surgical antibiotic prophylactics. Ceftriaxone and cefotaxime is not recommended for use as a surgical antibiotic prophylaxis in order that the third-generation of cephalosporin can be used for the treatment of patients with serious sepsis [10-16].

However, based on some previous research ceftriaxone and cefotaxime have also been used as prophylactic antibiotics in several hospitals worldwide. Administration of ceftriaxone as antibiotic prophylaxis has been shown to be more effective to reduce the incidence of SSI $[17,18]$, in which a single dose of ceftriaxone significantly reduces the risk of SSIs and its use has been proven to save medical costs [19]. Malhotra et al. (2013) found that the maximum sensitivity of the organisms isolated from SSI was to ceftriaxone [20]. However, the use of thirdgeneration cephalosporin excessively for surgical prophylaxis can increase the population of methicillin-resistant Staphylococcus aureus [21]. The emergence of extended spectrum beta-lactamase, vancomycin-resistant enterococci, and Clostridium difficile has also been widely reported to be associated with the inappropriate use of third generation cephalosporin [22]. In general, non-compliance with the guidelines for surgical prophylaxis is due to a lack of awareness of the guidelines, the availability of prophylactic antibiotics, and the belief that broad-spectrum antibiotics to be more effective in preventing SSIs compare with the narrow spectrum antibiotic prophylaxis [23-25]. To improve the level of compliance with the guidelines for the use of surgical antibiotic prophylaxis requires collaboration among health professions. Clinical pharmacists have an important role to assure the proper use of prophylactic antibiotics and collaborate with other health professionals to establish a local guideline. Mapping the sensitivity patterns of bacterial pathogens isolated from the operating room should be done regularly to develop local antibiotic guidelines to optimize the use of surgical prophylactic antibiotics.

\section{CONCLUSION}

This study showed that the adherence to the guidelines of prophylactic antibiotics for surgical antibiotic prophylaxis still needs to be improved. Collaboration among health professions is needed to create a local guideline for the use of prophylactic antibiotics, to improve the compliance of the surgeon in using the surgical antibiotic prophylaxis.

\section{ACKNOWLEDGMENTS}

We would like to express our thank Director of Dr. H. Marzoeki Mahdi Hospital, Bogor, for research collaboration with Graduate Program of Faculty of Pharmacy, University of Indonesia. We also express gratitude to all staffs in the Department of Surgery for their supports.

\section{REFERENCES}

1. Mangram AJ, Horan TC, Pearson ML, Silver LC, Jarvis WR. The hospital infection control practices advisory committee. Guideline for the prevention of surgical site infection. Infect Control Hosp Epidemiol 1999;20:247-80.

2. Leaper DJ, van Goor H, Reilly J, Petrosillo N, Geiss HK, Torres AJ, et al. Surgical site infection-a European perspective of incidence and economic burden. Int Wound J 2004;1(4):247-73.

3. Akalin S, Kutlu SS, Cirak B, Eskiçorapci SY, Bagdatli D, Akkaya S. Application of ATC/DDD methodology to evaluate perioperative antimicrobial prophylaxis. Int $\mathrm{J}$ Clin Pharm 2012;34(1):120-6.

4. Matti PR, Querol RC, Velmonte MA, Vera RL, Alejandria M, Prescribing practices of surgeons and factors that limit adherence to the Philippine college of surgeons clinical practice guidelines on antimicrobial prophylaxis for elective surgical procedures at the UP-PGH surgical wards. Philipp J Microbiol Infect Dis 2002;31(3):107-24.

5. Radji M, Aini F, Fauziyah S. Evaluation of antibiotic prophylaxis administration at the orthopedic surgery clinic of tertiary hospital in Jakarta, Indonesia. Asian Pac J Trop Dis 2014;4(3):190-3.

6. Radji M, Fathni R, Fauziyah S. Evaluation of surgical antibiotics prophylaxis in tertiary care hospital in Jakarta Indonesia. Experiment 2014;18(4):1292-6.

7. Ng RS, Chong CP. Surgeons' adherence to guidelines for surgical antimicrobial prophylaxis-a review. Australas Med J 2012;5(10):534-40.

8. Desiana LS, Soemardi A, Radji M. Evaluation of prophylactic antibiotic administration at the surgical ward of Dharmais Cancer Hospital, Jakarta. Indonesian J Cancer 2008;2(4):126-31.

9. Brethis CS, Thamizharasan S, Sridevi SA, Kalaiselvi B, Singh MB, Vijaykumar K. A prospective study of the pattern of use of antimicrobial agents in surgical prophylaxis in a tertiary care centre. Int J Pharm Pharm Sci 2017;9(1):283-7.

10. Scottish Intercollegiate Guidelines Network (SIGN). Guidelines 104. Antibiotic Prophylaxis in Surgery. A National Clinical Guideline. Edinburgh, UK: SIGN; 2008. Available from: http://www.sign.ac.uk/ pdf/sign 104.pdf.

11. Al-Mulhim FA, Baragbah MA, Sadat-Ali M, Alomran AS, Azam MQ. Prevalence of surgical site infection in orthopedic surgery: A 5-year analysis. Int Surg 2014;99(3):264-8.

12. Mawalla B, Mshana SE, Chalya PL, Imirzalioglu C, Mahalu W. Predictors of surgical site infections among patients undergoing major surgery at Bugando medical centre in north western Tanzania. BMC Surg 2010;11:21.12

13. Anvikar AR, Deshmukh AB, Karyakarte RP, Damle AS, Patwardhan NS, Malik AK, et al. One year prospective study of 3,280 surgical wounds. Indian J Med Microb 1999;17:129-32.

14. Bachoura A, Guitton TG, Smith RM, Vrahas MS, Zurakowski D, Ring D. Infirmity and injury complexity are risk factors for surgicalsite infection after operative fracture care. Clin Orthop Relat Res 2011;469(9):2621-30.

15. American Society of Health System Pharmacists. Therapeutic guidelines on antimicrobial prophylaxis in surgery. Am J Health Syst Pharm 1999;56(18):1839-88. 
16. Bratzler DW, Dellinger EP, Olsen KM, Perl TM, Auwaerter PG, Bolon $\mathrm{MK}$, et al. Clinical practice guidelines for antimicrobial prophylaxis in surgery. Am J Health Syst Pharm 2013;70(3):195-283.

17. Esposito S, Noviello S, Vanasia A, Venturino P. Ceftriaxone versus other antibiotics for surgical prophylaxis: A meta-analysis. Clin Drug Investig 2004;24(1):29-39.

18. Kigera JW, Turyakira C. Audit of prophylactic antibiotic use in orthopaedic surgery in Mulago hospital. Ann Afr Surg 2012;9:16-8.

19. Gillespie WJ, Walenkamp G. Antibiotic prophylaxis for surgery for proximal femoral and other closed long bone fractures. Cochrane Database Syst Rev 2010. DOI: 10.1002/14651858.CD000244.pub2.

20. Malhotra R, Singla B, Walia G. Incidence of postoperative wound infection by aerob with special reference to methicillin resistant Staphylococcue aureus. Int J Pharm Pharm Sci 2013;5(4):392-6.

21. Fukatsu K, Saito H, Matsuda T, Ikeda S, Furukawa S, Muto T. Influences of type and duration of antimicrobial prophylaxis on an outbreak of methicillin-resistant Staphylococcus aureus and on the incidence of wound infection. Arch Surg 1997;132(12):1320-5.

22. Dancer SJ. The problem with cephalosporins. J Antimicrob Chemother 2001;48(4):463-78.

23. Khan SA, Rodrigues G, Kumar P, Rao PG. Current challenges in adherence to clinical guidelines for antibiotic prophylaxis in surgery. J Coll Physicians Surg Pak 2006;16(6):435-7.

24. Pons-Busom M, Aguas-Compaired M, Delás J, Eguileor-Partearroyo B. Compliance with local guidelines for antibiotic prophylaxis in surgery. Infect Control Hosp Epidemiol 2004;25(4):308-12.

25. Parulekar L, Soman R, Singhal T, Rodrigues C, Dastur FD, Mehta A. How good is compliance with surgical antibiotic prophylaxis guidelines in a tertiary care private hospital in India? A prospective study. Indian J Surg 2009;71:15-8. 